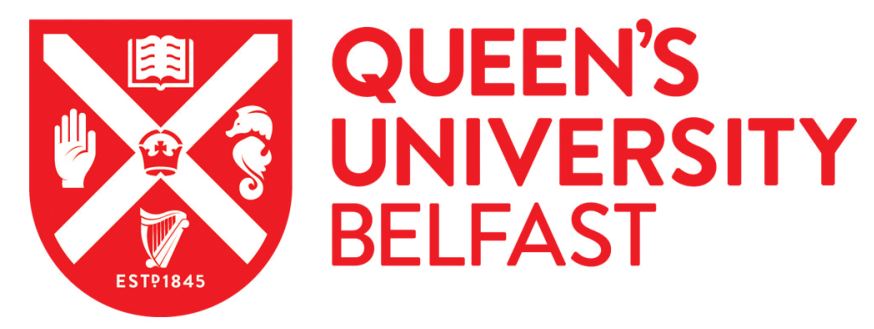

\title{
Does consideration of future consequences moderate the relationship between aggression and alcohol use in adolescents? Results from the United Kingdom
}

McKay, M. T., Dempster, M., \& Mello, Z. (2015). Does consideration of future consequences moderate the relationship between aggression and alcohol use in adolescents? Results from the United Kingdom. Addiction Research and Theory, 23(5), 372-379. https://doi.org/10.3109/16066359.2015.1009830

Published in:

Addiction Research and Theory

Document Version:

Peer reviewed version

Queen's University Belfast - Research Portal:

Link to publication record in Queen's University Belfast Research Portal

\author{
Publisher rights \\ (ङ) 2015 Taylor and Francis \\ The Version of Record of this manuscript has been published and is available in \\ Addiction Research and Theory Vol 23 Issue 5, 2015 http://www.tandfonline.com/doi/pdf/10.3109/16066359.2015.1009830
}

\section{General rights}

Copyright for the publications made accessible via the Queen's University Belfast Research Portal is retained by the author(s) and / or other copyright owners and it is a condition of accessing these publications that users recognise and abide by the legal requirements associated with these rights.

Take down policy

The Research Portal is Queen's institutional repository that provides access to Queen's research output. Every effort has been made to ensure that content in the Research Portal does not infringe any person's rights, or applicable UK laws. If you discover content in the

Research Portal that you believe breaches copyright or violates any law, please contact openaccess@qub.ac.uk. 


\title{
Does Consideration of Future Consequences moderate the relationship between aggression and alcohol use in adolescents? Results from the United Kingdom
}

\begin{abstract}
Background. An increasing body of literature suggests that those who give greater consideration to the future consequences (CFC) of their present behaviours are at a reduced risk of negative health outcomes. The present study examined whether CFC moderated the relationship between four domains of aggression and alcohol use in adolescents in the United Kindgom.
\end{abstract}

Methods. Participants were 1058 adolescents from Northern Ireland. Participants completed questionnaires assessing: Anger; Hostility; Verbal Aggression; Physical Aggression; Consideration of Future Consequences; and alcohol use.

Results. In line with extant research males scored significantly higher than females on measures of verbal and physical aggression, with no significant gender differences observed for other dependent measures. Results also revealed that CFC moderated the relationship between aggression and alcohol use, but only for females.

Conclusions. These findings add to the increasing body of literature examining the temporalhealth relationship. However more work is needed to help untangle the gender-specific effects.

Keywords: Consideration of Future Consequences; Alcohol; Aggression; Moderation 


\section{Introduction}

Research has pointed to a significant relationship between earlier initiation and later problematic misuse of alcohol (e.g., Bonomo, Bowes, Coffey, Carlin \& Patton, 2004). However, despite a large amount of research in the area, it has been suggested that evidence for a direct causal relationship between adolescent drinking and its impact on adult health is inconclusive (McCambridge, McAlaney \& Rowe, 2011). The complexity of the relationship between earlier use and later problems appears to be confounded by, for example, with problem behaviours and/or behavioural disinhibition (e.g., Donovan \& Molina, 2011), and some have concluded that earlier initiation is better characterised as a marker of risk, rather than a causal influence. Indeed Rossow \& Kuntsche (2013) concluded that earlier onset drinking was not responsible for later heavy drinking, except as part of a wider array of conduct problems.

Most classifications in the literature show two kinds of aggression, even if different names are used: Hostile Aggression (variously known as 'reactive, impulsive, or affective') is an act primarily oriented to hurt another individual; and Instrumental Aggression (variously known as 'proactive, premeditated, or predative') is a means or tool for solving problems or for obtaining a variety of objectives. According to Buss (1961), aggression is more than aggressive acts. In fact Buss (1961) distinguished three dimensions of aggression namely; physical-verbal, direct-indirect and active-passive. Accordingly aggression and anger are related but distinct constructs meaning that not all anger necessarily leads to physical or verbal aggression (Kerr \& Schneider, 2008). Aggression, as subsequently conceptualised by Buss and Perry (1992) can be assessed in four domains: Physical Aggression, Verbal Aggression, Anger and Hostility. Physical and verbal aggression represent instrumental or motor components of aggression, anger represents the emotional or affective component of 
aggression, while hostility represents the cognitive component (Reyna, Lello, Sanchez, \& Brussino, 2011).

Prospective studies in aggression have suggested that it is a risk factor, a long-term characteristic of drug-using individuals, and it has been suggested that acute administration of alcohol and/or drugs may merely exacerbate underlying aggressive tendencies (Allen, Moeller, Rhoades \& Cherek, 1997; Boles \& Miotto, 2003). In particular a large body of research has supported the hypothesis that childhood aggression typically precedes substance use (e.g., Fothergill \& Ensminger, 2006; Juon, Doherty, \& Ensminger, 2006; Pardini, White, \& Stouthamer Loeber, 2007). Using a latent class analysis Percy and Iwaniec (2010) reported that behavioural under-control was a key predictor of adolescent drinking patterns across all types of drinking with the exclusion of the higher end drinking where there were no differences between heavy and hazardous drinkers on behavioural under-control indicators. In a cross sectional study of university undergraduates Tremblay \& Ewart (2005) reported that physical aggression (but not verbal aggression, anger or hostility) was significantly associated with number of drinks per occasion and number of occasions when greater than 5 drinks were consumed.

Specifically childhood proactive aggression has been argued to be a risk factor for substance use (Connor, Steingard, Anderson, \& Melloni, 2003; Fite, Colder, Lochman, \& Wells, 2008; Fite, Colder, Lochman, \& Wells, 2007; Fite, Raine, Loeber, Stouthamer-Loeber \& Pardini, 2010; Miller \& Lynam, 2006; Pulkkinen, 1996). However, the link between reactive aggression and substance use is less clear, with inconsistent findings across studies (Fite, Schwartz \& Hendrickson, 2012). Two studies have found no significant association between reactive aggression and substance use (Miller \& Lynam, 2006; Pulkkinen, 1996). Yet other 
studies have demonstrated an association between reactive aggression and substance use (e.g., Connor et al., 2003; Fite et al., 2010).

Important gender differences have been observed. For example, in a one year follow-up study, Skara et al., (2008) examined physical aggression, relational aggression (deriding, excluding, or lying about a peer) and 4 types of drugs (alcohol, cigarettes, marijuana and hard drugs). Only physical aggression predicted alcohol use, and for males only (i.e. the effect was moderated by gender). Relational aggression was moderated by gender so that it predicted later cigarette and marijuana use for females. Relational aggression predicted alcohol and hard drug use for males and females.

The Consideration of Future Consequences (CFC; Strathman, Gleicher, Boninger \& Edwards, 1994) describes the extent to which people consider the potential distant outcomes of their current behaviours and the extent to which they are influenced by these potential outcomes. Although the construct is studied and discussed within the broader area of time perspective, it represents something more specific that a general preoccupation with the future. While future time perspective (e.g., Zimbardo \& Boyd, 1999) might be considered a vague and overarching concept, CFC involves a simultaneous assessment of present actions and future outcomes. Thus, although the outcome focus is in the future, the action, or decision to act is happening in the present. Higher CFC has been positively correlated with personality traits related to self-control including conscientiousness and delay of gratification (Strathman et al., 1994), and negatively correlated with impulsivity (Joireman, Anderson \& Strathman, 2003). 
A growing body of literature suggests that those who give greater consideration to the future consequences of present behaviours are also less likely to engage in health-compromising behaviours and generally live more healthy lifestyles. Those higher in CFC have been found to be more likely to exercise frequently (Ouellette, 2005), sleep better (Peters, Joireman \& Ridgway, 2005), be more likely to engage in safer sexual behaviour (Appleby, Marks, Miller, Murphy \& Mansergh, 2005), to participate in health screening (Orbell \& Hagger, 2006), drink less problematically (Beenstock, Adams \& White, 2011) have lower levels of obesity and to smoke less (Adams \& Nettle, 2009). In short, individuals high in CFC are expected to focus more on the future implications and consequences of their behaviour, and accordingly to modify current behaviours (Rappange, Brouwer \& van Exel, 2009). Robbins and Bryan (2004) reported that those adolescents who were oriented to the future were less likely to use drugs, had fewer alcohol problems, and perceived the risks attached with these risky behaviours. A greater present orientation was found to be positively related to risk behaviours such as alcohol use and cigarette smoking, a finding supported elsewhere (e.g. Wills, Sandy \& Yaeger, 2001).

Beyond health, the CFC construct has been shown to be significantly associated with behavioural self-regulation. For example those higher in CFCF have been shown to be less aggressive generally (Joireman et al., 2003), and less likely to engage in aggressive driving (Moore \& Dahlen, 2008), impulsive buying (Joireman, Sprott \& Spangenberg, 2005), compulsive buying (Joireman, Kees \& Sprott, 2010), and have been more likely to financially plan for the future (Webley \& Nyhus, 2006). The present study sought to investigate the extent (if any) to which consideration of future consequences might moderate the relationship between adolescent aggression and adolescent alcohol use. Further, it sought to contribute 
toward the vastly inconsistent research on gender differences in the relationship among CFC, aggression, and alcohol use.

\section{Methods}

\section{Sample}

Participants were school children $(n=1058)$ from High schools in the Greater Belfast Area in Northern Ireland (NI). Schools were randomly chosen to reflect the overall demographics of the area. A total of 12 schools were recruited for participation in a series of alcohol-related studies. All schools approached agreed to participate. Schools were asked to provide between 20 and 25 pupils from each of school grades 8-12 (ages 12-16). The study received ethical approval from the Ethics Committee at the University of Liverpool.

\section{Measures}

Consideration of Future Consequences

The Consideration of Future Consequences Scale (CFCS; Strathman et al., 1994) is a 12-item scale made up of five positively worded items and seven negatively worded items. Each of the positively worded items deals with intentional and active efforts to consider future consequences (e.g., I think it is important to take warnings about negative outcomes seriously even if the negative outcome will not occur for many years), while the negatively worded items deal with intentional and active efforts to concern one with immediate outcomes (e.g., $I$ think that sacrificing now is usually unnecessary since future outcomes can be dealt with at a later time). Responses were on a five-point Likert-type scale from 'very untrue of me' (scored 1) to 'very true of me’ (scored 5). The scale has demonstrated good psychometric 
properties, with $\alpha$ coefficients of $0.80-0.86\left(\alpha_{\text {current study }}=.78\right)$ and a 2-week test-retest reliability of 0.76 , and a 5-week test-retest reliability of 0.72 (Strathman et al., 1994).

\section{Aggression}

The Aggression Questionnaire (AQ; Buss \& Perry, 1992) consists of 29 items that represent our subscales of the questionnaire: (1) verbal aggression, (2) physical aggression, (3) anger and (4) hostility. Internal consistency reliability reported by Buss and Perry (1992) was as follows: physical aggression, (Cronbach's $\alpha=0.85$; $\left.\alpha_{\text {current study }}=.88\right)$, verbal aggression $=$ $0.72 ; \alpha_{\text {current study }}=.71$, anger $=0.83 ; \alpha_{\text {current study }}=.83$, hostility $=0.73 ; \alpha_{\text {current study }}=.69$, and the total score $=0.89$, indicating adequate internal consistency (Buss \& Perry, 1992). Testretest coefficients were also found to have acceptable reliability (Buss \& Perry, 1992).

\section{Alcohol Use}

The Adolescent Alcohol Involvement Scale (AAIS; Mayer \& Filstead, 1979) is a 14-item self-report screening measure for alcohol abuse in adolescents. In respect of alcohol research, it serves to help identify adolescents whose alcohol use impacts adversely on psychological functioning, social relations and/or family life. Questions are answered on a Likert scale allowing for a highest possible score of 79. The scale has demonstrated good psychometric properties and in a meta-analysis of adolescent alcohol screening measures, Shields et al. (2008) reported that among AAIS-administered samples made up of at least $80 \%$ Caucasians, the average reliability estimate was $0.86\left(\alpha_{\text {current study }}=.81\right)$, compared to a single study that administered the AAIS to an all-African American sample yielding a reliability estimate of 0.62. Given the demographics of the present sample, the AAIS was considered an appropriate measurement tool. 


\section{Procedure}

Data were gathered under examination-like conditions. Participants were issued with a set of response sheets and all questionnaires were administered verbally by the researcher, allowing pupils with literacy difficulties to take part and also to help maximise the number of fully completed response sheets. This meant that those with reading difficulties did not have to read the questions, and afforded all participants the opportunity to ask for clarification on any of the questions asked. Data collection took approximately 30 min in each school. An 'opt out' passive consent, approved by the University of Liverpool Ethics Committee, ensured that parents received detailed information on the study and were only required to respond if they were unhappy about their child's participation. On the day of the data collection, each participant gave their own informed consent to be involved.

\section{Analyses}

Firstly, independent samples $t$-tests were computed in order to examine sex differences on dependent measures. Additionally Pearson's correlations (two-tailed) were computed to examine the relationship between dependent measures. Finally tests of moderation were computed using the Andrew Hayes PROCESS download for SPSS (see www.afhayes.com). All analyses were performed using SPSS V.20.

\section{Results}

A total of 1106 school children participated of whom 1058 (96\%) were included in the analyses. A total of 48 respondents were eliminated as their completed questionnaires were spoiled with the inclusion of multiple responses. Table 1 displays the means, standard deviations and results of independent samples t-tests for sex and dependent measures. Results show that males scored significantly higher on measures of verbal aggression and physical 
aggression. There was no significant difference between males and females in respect of CFC, anger, hostility or AAIS score.

Insert Table 1

Table 2 displays the results of Pearson's correlations between measures. Where there were significant correlations between CFC or AAIS score and measures of aggression, the coefficients were generally 'small' (<.3) in nature (Cohen, 1988).

Insert Table 2

In order to examine the relationship between sex, aggression and CFC, a series of exploratory hierarchical linear regression models were computed examining predictors of AAIS score. AAIS score was entered as the dependent variable, sex was entered at step one and CFC and aggression scores entered at step two. A total of four separate models were then computed. In each model a three-way interaction term (sex x aggression domain x CFC) was entered at step three. After entering the interaction term for each aggression domain both Step 3 and the final model were significant, indicating that the interaction between sex, aggression domain and CFC provided a significant increase in the variance in AAIS score as explained by the model. Specifically the following were the step 3 and final model statistics: anger, $\left(\Delta \mathrm{R}^{2}\right.$ $=0.009, \Delta \mathrm{F}=11.90, \mathrm{p}<0.01)$ and $\mathrm{F}(7,1050)=29.17, \mathrm{p}<0.001$, indicating that the interaction between sex, anger and CFC $(\beta=-0.28, \mathrm{t}=-3.45, \mathrm{p}<0.01)$ provided a significant increase in the variance in AAIS score; hostility, $\left(\Delta \mathrm{R}^{2}=0.008, \Delta \mathrm{F}=10.21, \mathrm{p}<0.01\right)$ and $\mathrm{F}(7,1050)=28.88, \mathrm{p}<0.001$, indicating that the interaction between sex, hostility and CFC $(\beta=-0.26, \mathrm{t}=-3.20, \mathrm{p}<0.01)$ provided a significant increase in the variance in AAIS 
score; verbal aggression, $\left(\Delta \mathrm{R}^{2}=0.011, \Delta \mathrm{F}=13.67, \mathrm{p}<0.001\right)$ and $\mathrm{F}(7,1050)=29.47, \mathrm{p}<$ 0.001, indicating that the interaction between sex, verbal aggression and CFC $(\beta=-0.29, \mathrm{t}=-$ 3.70, $\mathrm{p}<0.001$ ) provided a significant increase in the variance in AAIS score; physical aggression, $\left(\Delta \mathrm{R}^{2}=0.021, \Delta \mathrm{F}=26.24, \mathrm{p}<0.001\right)$ and $\mathrm{F}(7,1050)=31.59, \mathrm{p}<0.001$, indicating that the interaction between sex, physical aggression and $\mathrm{CFC}(\beta=-0.37, \mathrm{t}=-5.12$, $\mathrm{p}<0.001)$ provided a significant increase in the variance in AAIS score.

On the basis of the results of these exploratory analyses a number of more detailed sexspecific analyses were undertaken. Tests of moderation were performed for each of the aggression domains (anger, hostility, physical and verbal aggression). Table 3 displays the results of tests of moderation for males and females.

Insert Table 3

Results show that there was no significant moderation by CFC factor in the relationship between aggression and AAIS score among males. However, results also show that for females in all but CFC $\mathrm{x}$ anger, CFC significantly moderated the relationship between aggression and AAIS score.

Results indicated that lower CFC and higher hostility were both significantly associated with higher AAIS score. CFC $\mathrm{x}$ hostility was also significant $(\mathrm{b}=-0.06, \mathrm{p}<.01)$ suggesting that the effect of hostility on AAIS score is moderated by CFC. Simple slopes for the association between hostility and AAIS score were tested for low (-1 SD below the mean), moderate (mean), and high (+1 SD above the mean) levels of CFC. Simple slopes analyses were only 
significant for moderate $(\mathrm{b}=0.56, \mathrm{p}<.001)$ or high $(\mathrm{b}=0.94, \mathrm{p}<.001)$ levels of CFC, but not for lower levels $(\mathrm{b}=0.18, \mathrm{p}=.27)$.

Lower CFC and higher verbal aggression were significantly associated with higher AAIS score. CFC x verbal aggression $(b=-0.08, p<.05)$ was also significant. Simple slopes analyses were significant for low $(b=1.94, \mathrm{p}<.001)$, moderate $(\mathrm{b}=1.45, \mathrm{p}<.001)$ and high $(\mathrm{b}=0.95, \mathrm{p}<.01)$ levels of CFC.

Finally, lower levels of CFC-F and physical aggression were significantly associated with higher AAIS score. CFC $x$ physical aggression $(b=-0.04, \mathrm{p}<.01)$ was also significant. Simple slopes analyses were significant for low $(0.81, \mathrm{p}<.001)$, moderate $(\mathrm{b}=0.58, \mathrm{p}<.001)$ and high $(\mathrm{b}=0.34, \mathrm{p}=.01)$ levels of CFC.

\section{Insert Figure 1}

\section{Discussion}

The present study examined the extent to which CFC moderated the relationship between four domains of aggression and composite alcohol use scores in a large sample of adolescents. Results revealed that moderation occurred only among females. As previously stated, the CFC construct is hypothesised to measure the extent to which consideration of future consequences influences current behaviour. The present study reveals that this consideration reduces or 'dumbs down' the well-established (in other literature) and observed (in the main effects of the present study) relationship between disinhibited behaviour (as measured by aggression) and alcohol use behaviours, but only for females. The study findings must be interpreted in the context of some important limitations. Firstly, all data were obtained through self-report, although confidentiality and anonymity were guaranteed to participants. Secondly, all participants were from schools in the Greater Belfast area of 
Northern Ireland, calling into question the generalizability of results. However, against these limitations are the facts that the study employed a large sample and used well established measures.

The results of the present study reveal that males scored significantly higher than females on measures of instrumental aggression, a finding broadly supported in the aggression literature (Buss \& Perry, 1991; Tremblay \& Ewart, 2005; Abd-El-Fattah, 2013). Moreover the lack of a significant difference on AAIS score between males and females reflects recent evidence suggesting that a convergence has taken place such that girls are as likely as boys to drink problematically (Eisenbach-Stangl \& Thom, 2009; Health Promotion Agency, 2005; Northern Ireland Statistics and Research Agency, 2008). Finally the significant 'main effects’ relationships between higher aggression, lower CFC and higher AAIS score are all in line with the literature discussed in the introduction. However, the fact that moderation was only observed for females and not males is both difficult to explain, and potentially a less useful finding in terms of the potential for prevention of alcohol problems among adolescents.

For adults and adolescents, risky behaviour has been shown to be associated with anticipated positive consequences (Galvan, Hare, Voss, Glover \& Casey, 2007). One study of costs/benefit analyses in adolescents showed that in general, the costs which adolescents anticipate are more important than the anticipated benefits in determining risky healthcompromising behaviours (Small et al., 1993). Adolescents who do not engage in risky behaviours have been shown to anticipate significantly more costs to the behaviours relative to their risk-taking peers (Small Silverberg \& Kerns, 1993; Galvan et al., 2007). 
The extension of future time perspective has been shown to be measurable on at least two levels namely the cognitive and the cognitive-motivational (or dynamic) (e.g., Husman \& Shell, 2008). The cognitive dimension relates to the ability to look far ahead into the future. With a deeper future, present actions acquire a higher utility value (Eccles \& Wigfield, 2002), According to Bandura (2001) future events cannot be responsible for current motivation and action because they do not yet actually exist. However cognitive representation of future events in the present allows them to be converted into current motivators and regulators of behaviour, thus behaviour is motivated and directed by projected goals and anticipated outcomes rather than an unrealized future state. As a behavioural assessment of future orientation, one explanation for the moderation results in the present study might be that females, more than males, are better able to translate the cognitive awareness or understanding of the future into behaviour and/or behavioural intentions.

Specifically in terms of the moderating effect of CFC on drinking behavior for females, recent evidence suggests that differences in cognitive functioning and development between adolescent males and females are minimal (Hyde, 2014). However within the broader time perspective literature a number of issues might be relevant. Firstly, Steinberg and colleagues (2009) reported small but significant gender differences in terms of planning ahead, anticipation of future consequences and time perspective with females outscoring males in each case. Moreover, Harber, Zimbardo and Boyd (2003) found that individual differences in time perspective influenced how promptly and reliably students completed research obligations with more future oriented students enlisting in studies sooner than their peers. There was an observed gender effect with female "futures" starting their required experiments on average two weeks sooner, completing the middle portion of their 
experiments two-and-a-half weeks sooner, and completed their entire experiment quotas oneand-a-half weeks sooner, than did male "presents".

As elsewhere (e.g., Orbell \& Hagger, 2006; Oulette 2005) there were no significant gender differences in CFC scores, however, these results are at odds with others which have shown that females had higher CFC scores than males (e.g., Peters et al., 2005). Findings on gender differences in the relationship between CFC scores and various health outcomes are also mixed. In a multi-sample study, Keough, Zimbardo, and Boyd (1999) argued that variation in 'future' and 'present' time perspective scores were more related to substance use than gender. Rothspan and Read (1996) reported that for males only, Future Orientation scores were positively associated with healthy sexual behaviors, whereas the relationships as not observed for females.

Inconsistent gender differences were also observed in the relationship between aggression and substance use. White, Brick and Hansel (1993) demonstrated that the patterns of relationships between aggression and alcohol use were the opposite between genders. Specifically, among females, alcohol use predicted later aggression, whereas, for males, aggression predicted later alcohol use. In contrast, Bachman and Peralta (2002) indicated that alcohol and substance use were positively associated with violence for both females and males. Even still, Skara and colleagues (2008) showed how physical aggression predicted alcohol use for males but not for females, whereas relational aggression predicted cigarette and marijuana use for females but not for males.

The results of the present study need to be interpreted in light of a number of limitations. The data were all collected using self-report, and the participants were all in mainstream 
education. Moreover, as the data are cross sectional, the direction of the effects cannot be absolutely determined. However, in conclusion we can say that there is a complex relationship between consideration of future consequences, health behaviours and gender. The complexity might be a result of the different methods of assessing substance use and of assessing aggression. This complexity has been identified in the present study, but further work is required to disentangle the findings to promote their application.

\section{References}

Abd-El-Fattah, S.M. (2013). A cross-cultural examination of the Aggression QuestionnaireShort Form among Egyptian and Omani Adolescents. Journal of Personality Assessment, 95, 539-548.

Adams, J. (2012). Consideration of immediate and future consequences, smoking status, and body mass index. Health Psychology, 31, 260-263.

Adams, J. \& Nettle, D. (2009). Time perspective, personality and smoking, body mass and physical activity: An empirical study. British Journal of Health Psychology, 14, 83105.

Allen, T.J., Moeller, F.G., Rhoades, H.M. \& Cherek, D.R. (1997). Subjects with a history of drug dependence are more aggressive than subjects with no drug use history. Drug and Alcohol Dependence, 46, 95-103.

Appleby, P.R., Marks, A.A., Miller, L.C., Murphy, S., \& Mansergh, G. (2005). Consideration of future consequences and unprotected anal intercourse among men who have sex with men. Journal of Homosexuality, 50, 119-133. 
Bachman, R. \& Peralta, R. (2002). The relationship between drinking and violence in an adolescent population: does gender matter? Deviant Behavior, 23, 1-19.

Bandura, A. (2001). Social cognitive theory: an agentic perspective. Annual Review of Psychology, 52, 1-26.

Beenstock, J., Adams, J., \& White, M. (2011). The association between time perspective and alcohol consumption in university students: Cross-sectional study. The European Journal of Public Health, 21, 438-443.

Boles, S.M. \& Miotto, K. (2003). Substance abuse and violence: A review of the literature. Aggression and Violent Behavior, 8, 155-174.

Bonomo, Y.A., Bowes, G., Coffey, C., Carlin, J.B., \& Patton, C. (2004). Teenage drinking and the onset of alcohol dependence: A cohort study over seven years. Addiction, 99, $1520-1528$.

Buss, A.H. (1961). The psychology of aggression. New York: Wiley.

Buss, A.H., \& Perry, M. (1992). The Aggression Questionnaire. Journal of Personality and Social Psychology, 63, 452-459.

Cohen, J. (1988). Statistical Power Analysis for the Behavioral Sciences (second ed.). Lawrence Erlbaum Associates.

Connor, D. F., Steingard, R. J., Anderson, J. J., \& Melloni, R. H. (2003). Gender differences in reactive and proactive aggression. Child Psychiatry and Human Development, 33, 279-294.

Donovan, J.E. \& Molina B.S. (2011). Childhood risk factors for early on-set drinking. Journal of Studies on Alcohol and Drugs, 72, 741-751.

Eccles, J. S., \& Wigfield, A. (2002). Motivational beliefs, values and goals. Annual Review of Psychology, 53, 109-132. 
Eisenbach-Stangl, I. \& Thom, B. (2009). Intoxication and Intoxicated Behaviour in Contemporary European Cultures: Myths, Realities and the Implications for Policy, (Prevention) Practice and Research. Policy Brief (February) European Centre for Social Welfare, Policy and Research, Vienna.

Fite, P. J., Colder, C. R., Lochman, J. E., \& Wells, K. C. (2007). Pathways from proactive and reactive aggression to substance use. Psychology of Addictive Behaviors, 21, 355-364.

Fite, P. J., Colder, C. R., Lochman, J. E., \& Wells, K. C. (2008). The relation between childhood proactive and reactive aggression and substance use initiation. Journal of Abnormal Child Psychology, 36, 261-271.

Fite, P. J., Raine, A., Loeber, R., Stouthamer-Loeber, M., \& Pardini, D. A. (2010). Reactive and Proactive Aggression in Adolescent Males: Examining Differential Outcomes 10-Years Later in Early Adulthood. Criminal Justice and Behavior, 37, 141-157.

Fite, P.J., Schwartz, S. \& Hendrickson, M. (2012). Childhood proactive and reactive aggression: Differential risk for substance use? Aggression and Violent Behavior, 17, 240-246.

Fothergill, K. E., \& Ensminger, M. E. (2006). Childhood and adolescent antecedents of drug and alcohol problems: A longitudinal study. Drug and Alcohol Dependence, 82, 6176.

Galvan, A., Hare, T., Voss, H., Glover, G. \& Casey, B.J. (2007). Risk-taking and the adolescent brain: who is at risk? Developmental Science, 10, F8-F14.

Harber, K.D., Zimbardo, P.G., \& Boyd, J.N. (2003). Participant self-selection biases as a function of individual differences in time perspective. Basic and Applied Social Psychology, 25, 255-264. 
Health Promotion Agency, HPA (2005). Drinking behaviour among young people in Northern Ireland: Secondary analysis of alcohol data from 1997 to 2003. Belfast: Health Promotion Agency.

Husman, J. \& Shell, D.F. (2008). Beliefs and perceptions about the future: A measurement of future time perspective. Learning and Individual Differences, 18, 166-175.

Joireman, J., Anderson, J. \& Strathman, A. (2003). The Aggression Paradox: Understanding Links Among Aggression, Sensation Seeking, and the Consideration of Future Consequences. Journal of Personality and Social Psychology, 84, 1287-1302.

Joireman, J., Sprott, D., \& Spangenberg, E. (2005). Fiscal responsibility and the consideration of future consequences. Personality and Individual Differences, 39, 1159-1168.

Joireman, J., Balliet, D., Sprott, D., Spangenberg, E. \& Schultz, J. (2008). Consideration of future consequences, ego-depletion, and self-control: Support for distinguishing between CFC-Immediate and CFC-Future sub-scales. Personality and Individual Differences, 45, 15-21.

Joireman, J., Kees, J., \& Sprott, D. (2010). Concern with immediate consequences magnifies the impact of compulsive buying tendencies on college students’ credit card debt. Journal of Consumer Affairs, 44, 155-178.

Juon, H. S., Doherty, E. E., \& Ensminger, M. E. (2006). Childhood Behavior and Adult Criminality: Cluster Analysis in a Prospective Study of African Americans. Journal of Quantitative Criminology, 21, 193-214.

Keough, K.A., Zimbardo, P.G., \& Boyd, J.N. (1999). Time perspective as a predictor of substance use. Basic and Applied Social Psychology, 21, 149-164.

Kerr, M.A. \& Schneider, B. H. (2008). Anger expression in children and adolescents: A review of the empirical literature. Clinical Psychology Review, 28, 559-577. 
Mayer, J., \& Filstead, W.J. (1979). The adolescent alcohol involvement scale. Journal of Studies on Alcohol, 40, 291-300.

McCambridge, J., McAlaney, J. \& Rowe, R. (2011). Adult consequences of late adolescent alcohol consumption: a systematic review of cohort studies. PLoS medicine, 8 (2).

Miller, J. D., \& Lynam, D. R. (2006). Reactive and proactive aggression: Similarities and differences. Personality and Individual Differences, 41, 1469-1480.

Moore, M. \& Dahlen, E.R. (2008). Forgiveness and consideration of future consequences in aggressive driving. Accident Analysis and Prevention, 40, 1661-1666.

Northern Ireland Statistics and Research Agency (NISRA) (2008). Young Person's Behaviour and Attitudes Survey. Belfast: NISRA.

Orbell, S., \& Hagger, M.S. (2006). Temporal framing and the decision to take part in type 2 diabetes screening: Effects of individual differences in consideration of future consequences on persuasion. Health Psychology, 25, 537-548.

Ouellette, J. A., Hessling, R., Gibbons, F. X., Reis-Bergan, M., \& Gerrard, M. (2005). Using images to increase exercise behavior: Prototypes vs. possible selves. Personality and Social Psychology Bulletin, 31, 610-620.

Pardini, D., White, H. R., \& Stouthamer Loeber, M. (2007). Early adolescent sychopathology as a predictor of alcohol use disorders by young adulthood. Drug and Alcohol Dependence, 88, S38-S49.

Percy, A. \& Iwaniec, D. (2010). Teenage Drinking: Causes and Consequences. Saarbrücken: Lambert Academic Publishing.

Peters, B.R., Joireman, J. \& Ridgway, R.L. (2005) Individual differences in the consideration of future consequences scale correlate with sleep habits, sleep quality and GPA in university students. Psychological Reports, 96, 817-84. 
Pulkkinen, L. (1996). Proactive and reactive aggression in early adolescence as precursors to anti- and prosocial behavior in young adults. Aggressive Behavior, 22, $241-257$.

Rappange, D.R., Brouwer, W.B.F., \& Van Exel, N.J.A. (2009). Back to the Consideration of Future Consequences Scale: Time to Reconsider? The Journal of Social Psychology, $149,562-584$.

Reyna, C., Lello, M.G., Sanchez, A., \& Brussino, S. (2011). The Buss-Perry Aggression Questionnaire: Construct validity and gender invariance among Argentinean adolescents. International Journal of Psychological Research, 4, 30-37.

Rossow, I. \& Kuntsche, E. (2013). Early Onset of Drinking and Risk of Heavy Drinking in Young Adulthood - A 13-Year Prospective Study. Alcoholism: Clinical and Experimental Research, 37, E297-E304.

Robbins, R.N. \& Bryan, A. (2004). Relationships between Future Orientation, Impulsive Sensation Seeking, and Risk Behavior among Adjudicated Adolescents. Journal of Adolescent Research, 19, 428-445.

Rothspan, S. \& Read, S.J. (1996). Present versus future time perspective and HIV risk among heterosexual college students. Health Psychology, 15, 131-134.

Shields, A.L., Campfield, D.C., Miller, C.S., Howell, P.T., Wallace, K., \& Weiss, R.D. (2008). Score reliability of adolescent alcohol screening measures: A meta-analytic inquiry. Journal of Child and Adolescent Substance Abuse, 17, 75-97.

Skara, S., Pokhrel, P., Weiner, M.D. Sun, P., Dent, C.W. \& Sussman, S. (2008). Physical and relational aggression as predictors of drug use: Gender differences among high school students. Addictive Behaviors, 33, 1507-1515. 
Small, S.A., Silverberg, S.B., \& Kerns, D. (1993). Adolescents’ perceptions of the costs and benefits of engaging in health compromising behaviors. Journal of Youth and Adolescence, 22, 73-87.

Steinberg, L.. Graham, S., O’Brien, L., Woolard, J., Cauffman, E. \& Banich, M. (2009). Age Differences in Future Orientation and Delay Discounting. Child Development, 80, 28-44.

Strathman, A., Gleicher, F., Boninger, D.S. \& Edwards, C.S. (1994) The Consideration of Future Consequences: Weighing Immediate and Distant Outcomes of Behavior. Journal of Personality and Social Psychology, 66, 742-752.

Tremblay, P.F., \& Ewart, L.A. (2005).The Buss and Perry Aggression Questionnaire and its relations to values, the Big Five, provoking hypothetical situations, alcohol consumption patterns, and alcohol expectancies. Personality and Individual Differences, 38, 337-346.

Webley, P. \& Nyhus, E.K. (2006). Parents’ influence on children’s future orientation and saving. Journal of Economic Psychology, 27, 140-164.

White, H.R., Brick, J. \& Hansell, S. (1993). A longitudinal investigation of alcohol use and aggression in adolescence. Journal of Studies on Alcohol, 11, 62-77.

Wills, T.A., Sandy, J.M. \& Yaeger, A.M. (2001). Time Perspective and Early-Onset Substance Use: A Model Based on Stress-Coping Theory. Psychology of Addictive Behaviors, 118-125.

Zimbardo, P. G., \& Boyd, J. N. (1999). Time perspective: A valid, reliable individualdifferences metric. Journal of Personality and Social Psychology, 77, 1271-1288. 
Table 1 Descriptive data and independent samples $t$-tests for variables measured. Shown are means (+ standard deviation)

\begin{tabular}{|c|c|c|c|c|c|c|}
\hline & Males & & Female & & & \\
\hline & $(n=54$ & & $(n=515$ & & & \\
\hline & Mean & $S D$ & Mean & $S D$ & $t$-test & $p$-value \\
\hline Consideration of Future Consequences & 37.73 & 6.70 & 37.64 & 6.56 & $0.23(d f 1056)$ & 0.821 \\
\hline Anger & 22.16 & 5.77 & 21.74 & 5.69 & $1.19(d f 1056)$ & 0.234 \\
\hline Hostility & 22.73 & 5.09 & 23.12 & 5.39 & $-1.22(d f 1056)$ & 0.223 \\
\hline Verbal Aggression & 15.67 & 3.09 & 14.61 & 3.14 & $5.53(d f 1056)$ & 0.000 \\
\hline Physical Aggression & 28.78 & 7.37 & 23.50 & 7.98 & $11.19(\mathrm{df} 1056)$ & 0.000 \\
\hline AAIS score & 23.19 & 18.17 & 23.72 & 18.97 & $-0.47(d f 1056)$ & 0.642 \\
\hline
\end{tabular}


Table 2 Results of Spearman's $\rho$ correlations (two-tailed) between variables measured. Note: results for males above the diagonal

$\begin{array}{lllllll} & \text { CFC } & \text { A } & \text { H } & \text { VA } & \text { PA } & \text { AAIS } \\ \text { CFC } & - & -.18^{* *} & -.13^{* *} & -.15^{* *} & -.29 * * & -.18^{* *} \\ \mathbf{A} & -.12^{* *} & - & .40^{* *} & .42^{* *} & .60^{* *} & .30^{* *} \\ \mathbf{H} & .01 & .46^{* *} & - & .37 * * & .31^{* *} & .07 \\ \text { VA } & -.03 & .52^{* *} & .41^{* *} & - & .43^{* *} & .19 * * \\ \text { PA } & -.22^{* *} & .57^{* *} & .33^{* *} & .51^{* *} & - & .40^{* *} \\ \text { AAIS } & -.26^{* *} & .34^{* *} & .15^{* *} & .25^{* *} & .30^{* *} & -\end{array}$

$\mathrm{CFC}=$ Consideration of Future Consequences; $\mathrm{A}=$ Anger; $\mathrm{H}=$ Hostility; VA = Verbal Aggression; PA = Physical Aggression; AAIS = Adolescent Alcohol Involvement Scale. ${ }^{* *} \mathrm{p}<.01$ 
Table 3 Results of tests of the moderating effect of CFC on the relationship between aggression and alcohol use

\begin{tabular}{|c|c|c|c|c|c|c|c|c|c|}
\hline \multicolumn{5}{|c|}{ Males (n=543) } & \multicolumn{5}{|c|}{ Females $(n=515)$} \\
\hline $\boldsymbol{\beta}$ & $S E b$ & $\mathbf{t}$ & $p$-value & $\begin{array}{l}\text { LLCI, } \\
\text { ULCI }\end{array}$ & $\beta$ & $S E b$ & $\mathbf{t}$ & $p$-value & $\begin{array}{l}\text { LLCI, } \\
\text { ULCI }\end{array}$ \\
\hline-0.35 & 0.12 & -3.06 & 0.002 & $-0.58,-0.13$ & -0.58 & 0.12 & -4.80 & 0.000 & $-0.81,-0.34$ \\
\hline 0.90 & 0.13 & 7.09 & 0.000 & $0.65,1.15$ & 1.02 & 0.13 & 7.91 & 0.000 & $0.77,1.28$ \\
\hline-0.03 & 0.02 & -1.65 & 0.099 & $-0.06,0.01$ & -0.03 & 0.02 & -1.88 & 0.060 & -0.06 .0 .01 \\
\hline-0.54 & 0.12 & -4.67 & 0.000 & $-0.76,-0.31$ & -0.69 & 0.11 & -6.07 & 0.000 & $-0.92,-0.47$ \\
\hline 0.16 & 0.16 & 1.01 & 0.314 & $-0.15,0.47$ & 0.56 & 0.14 & 3.96 & 0.000 & $0.28,0.84$ \\
\hline
\end{tabular}




\begin{tabular}{|c|c|c|c|c|c|c|c|c|c|c|}
\hline CFC x Hostility & 0.03 & 0.02 & 1.20 & 0.229 & $-0.02,0.07$ & -0.06 & 0.02 & -3.53 & 0.000 & $-0.09,-0.03$ \\
\hline CFC & -0.44 & 0.11 & -3.80 & 0.000 & $-0.66,-0.21$ & -0.65 & 0.12 & -5.46 & 0.000 & $-0.88,-0.41$ \\
\hline Verbal Aggression & 1.10 & 0.24 & 4.59 & 0.000 & $0.63,1.57$ & 1.45 & 0.24 & 5.94 & 0.000 & $0.97,1.92$ \\
\hline CFC x Verbal Aggression & -0.01 & 0.04 & -0.23 & 0.821 & $-0.09,0.07$ & -0.08 & 0.04 & -2.17 & 0.031 & $-0.14,-0.01$ \\
\hline CFC & -0.20 & 0.12 & -1.65 & 0.101 & $-0.44,0.04$ & -0.55 & 0.12 & -4.61 & 0.000 & $-0.79,-0.32$ \\
\hline Physical Aggression & 0.94 & 0.09 & 9.90 & 0.000 & $0.75,1.12$ & 0.58 & 0.10 & 5.89 & 0.000 & 0.38re , 0.77 \\
\hline CFC x Physical Aggression & -0.01 & 0.01 & -0.69 & 0.490 & $-0.04,0.02$ & -0.04 & 0.01 & -2.91 & 0.004 & $-0.06,-0.01$ \\
\hline
\end{tabular}

CFC = Consideration of Future Consequences; $B=$ Beta; $S E$ b = Standard error of beta; LLCI = Lower Limit Confidence Interval;

ULCI = Upper Limit Confidence Interval 
